\title{
MSc degree in color technology for the automotive sector
}

F. Martinez-Verdu, E. Perales, E. Chorro, V. Viqueira, E. Gilabert

F. Martinez-Verdu, E. Perales, E. Chorro, V. Viqueira, E. Gilabert, "MSc degree in color technology for the automotive sector," Proc. SPIE 9289, 12th Education and Training in Optics and Photonics Conference, 928925 (17 July 2014); doi: 10.1117/12.2070722

SPIE Event: 12th Education and Training in Optics and Photonics Conference, 2013, Porto, Portugal 


\title{
MSc degree in Color Technology for the Automotive Sector
}

\author{
F. Martínez-Verdú*a ${ }^{\mathrm{a}}$, E. Perales ${ }^{\mathrm{a}}$, E. Chorro ${ }^{\mathrm{a}}$, V. Viqueira ${ }^{\mathrm{a}}$, E. Gilabert ${ }^{\mathrm{b}}$ \\ ${ }^{a}$ Color \& Vision Group, University Institute of Physics Applied to Sciences and Technologies, \\ University of Alicante, Carretera de San Vicente del Raspeig s/n, 03690 Alicante (Spain); \\ ${ }^{b}$ Department of Paper and Textile Engineering, Universitat Politècnica de València, Ferrándiz \& \\ Carbonell Square, 03801 Alcoy (Spain)
}

\begin{abstract}
Nowadays, the measurement and management of color quality of the gonio-apparent materials is complex, but highly demanded in many industrial sectors, as automotive, cosmetics, plastics for consumer electronics, printing inks, architectural coatings, etc. It is necessary to control complex instrumentation and to do visual assessments of texture and color differences to get, for instance, a visual harmony in car bodies; and a profound knowledge of physics and chemistry of special-effect pigments for their optical formulation to obtain attractive visual effects in coatings, plastics, etc, combining among them and with solid pigments. From University of Alicante, for the academic year 2013-14, we are organizing the first MSc degree in Color Technology for the Automotive Sector, with a design of contents embracing CIE colorimetry and visual perception, included the AUDI2000 color difference formula, instrumentation and color management software, fundamentals of coatings and plastics in the automotive sector, and, optical formulation of pigments. The MSc syllabus, with 60 ECTS, is designed to be taught in two semesters: from September to February with on classroom theoretical and practical activities, and, from March to June at virtual level, with internships of training in some companies. Therefore, the MSc Thesis would be the performance report during the internship in companies or research institutions. Some multinational companies, both as car makers and coatings and plastics providers, from European and non-European countries have already shown their support and interest in welcoming students for specific training, even some job offers when the first MSc edition finishes.
\end{abstract}

Keywords: Colorimetry, special-effect pigments, goniochromism, visual appearance, color \& texture, automotive coatings, visual harmony, training internships in company

\section{INTRODUCTION}

Color Technology focuses on the study of theories and techniques related to the design, manufacture and measurement of colored materials ${ }^{1}$. A wide range of different industrial sectors are involved in color technology (colorants, coatings, textiles, ceramics, plastics, printing, multimedia, etc.). Unfortunately, in many cases, color experts within these sectors have not received any specific training in colorimetry. Therefore, their knowledge about colors, which is critical to develop their work, has been obtained through practical, possibly self-taught, experience.

For this reason, companies involved in these productive sectors often invest considerable resources in specific color training to improve their employees' skills. In the same way, the limited number of graduates who do have advanced color training is highly sought after by many companies.

Over recent decades, color measurement and color quality control of gonio-apparent materials have become key areas for the automotive industry ${ }^{2}$ and also for other sectors such as cosmetics, coatings, plastics, printing, textiles, architecture, etc. Therefore, it is necessary to count on in-depth knowledge of complex instrumentation techniques and visual evaluation procedures as regards differences in color and texture (sparkle and graininess); and even color formulation with solid and special effect pigments ${ }^{1-6}$.

In response to this socio-economic demand, the Vision and Color Group of the Department of Optics, Pharmacology and Anatomy at the University of Alicante, in collaboration with other academic institutions (University of Granada - UGR, Technical University of Catalonia - UPC, Technical University of Valencia - UPV, and High Council of Scientific Research - CSIC) and different companies (AUDI, SEAT, BASF Coatings, BYK-Gardner, Mercedes Benz, PPG, Merck,

12th Education and Training in Optics and Photonics Conference, edited by

Manuel F. P. C. Martins Costa, Mourad Zghal, Proc. of SPIE Vol. 9289, 928925

(C) 2014 SPIE, OSA, IEEE, ICO · doi: 10.1117/12.2070722

Proc. of SPIE Vol. 9289 928925-1 
Valspar, Nubiola Group, etc), is offering the Master's Degree in Color Technology for the Automotive Sector postgraduate course with 60 ECTS or credits (Figure 1, with acronym ColTAS).

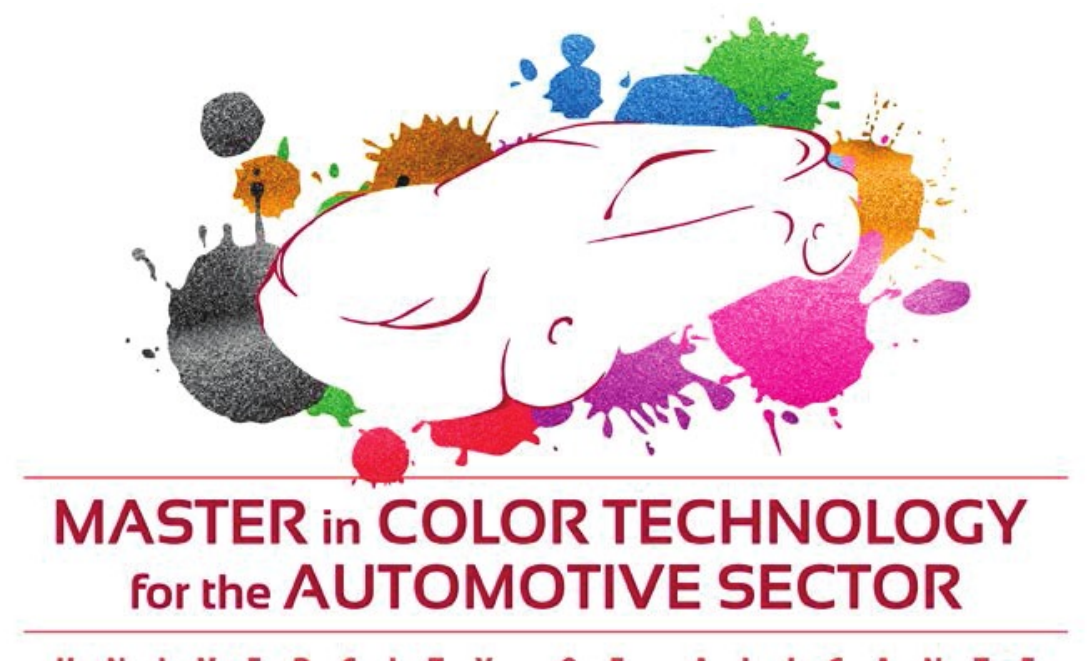

$\begin{array}{llllllllllllllllllll}\text { U N } & N & \text { I } & \text { V } & \text { E } & R & S & \text { I } & T & \text { Y } & \text { O } & \text { F } & \text { A } & \text { L } & \text { I } & \text { C } & \text { A } & \text { N } & \text { T } & \text { E }\end{array}$

Figure 1. Logotype of the MSc degree in Color Technology for the Automotive Sector.

\section{MISSION, COMPETENCES AND OBJECTIVES}

The purpose of ColTAS degree is to provide comprehensive training in the multidisciplinary study of Color Science and Technology from a global perspective. Students will learn the physicochemical and visual laws and solve real or simulated problems that often arise when using special effect pigments in different industrial sectors, particularly within the automotive sector (Figure 2).

This course includes an industry-based internship of up to 300 hours and provides a great opportunity to achieve basic and advanced color control skills at an industrial level, particularly in the automotive sector.

For color experts with a university degree, this new postgraduate course is a great chance to enhance training and professional qualifications. Meanwhile, recent graduates who choose to undertake this specialist postgraduate course will find it easier to obtain highly specialized jobs, which are therefore more highly valued (and better paid).

From the skills demanded by the industry, a series of contents and learning objectives intended to meet the following competencies has been planned as follows:

\subsection{General Key Competences (GKC)}

GKC1: Acquire advanced knowledge and skills in the field of Color Science \& Technology;

GKC2: Ability to critically trace and understand the last scientific-technological advances related to the special-effect pigments in some industrial sectors, particularly in the automotive sector;

GKC3: Ability to link knowledge and skills enabling to tackle problems from different views, enriching the solutions;

GKC4: Ability to carry out guided research or innovation works on the quality management of the visual harmony in cars at an advanced level;

GKC5: Develop originality and creativity when some specific color technology problems applied in some industrial sectors (automotive, cosmetics, architectural coatings, design, etc) should be tackled.

\subsection{Transversal Key Competences (TKC)}

TKC1: Skills of writing and oral communication in English and Spanish. Capability of making and advocating reports and projects; 
TKC2: Skills related to computer tools and ICTs, as well as database online access, scientific literature, patents and standards;

TKC3: Skills of adaptation, planning and organization in quality and effective making of autonomous works or inside interdisciplinary teams in front of new and / or real situations;

TKC4: Skills of leadership for taking sustainable, responsible, ethical, committed, consensual and efficient decisions.

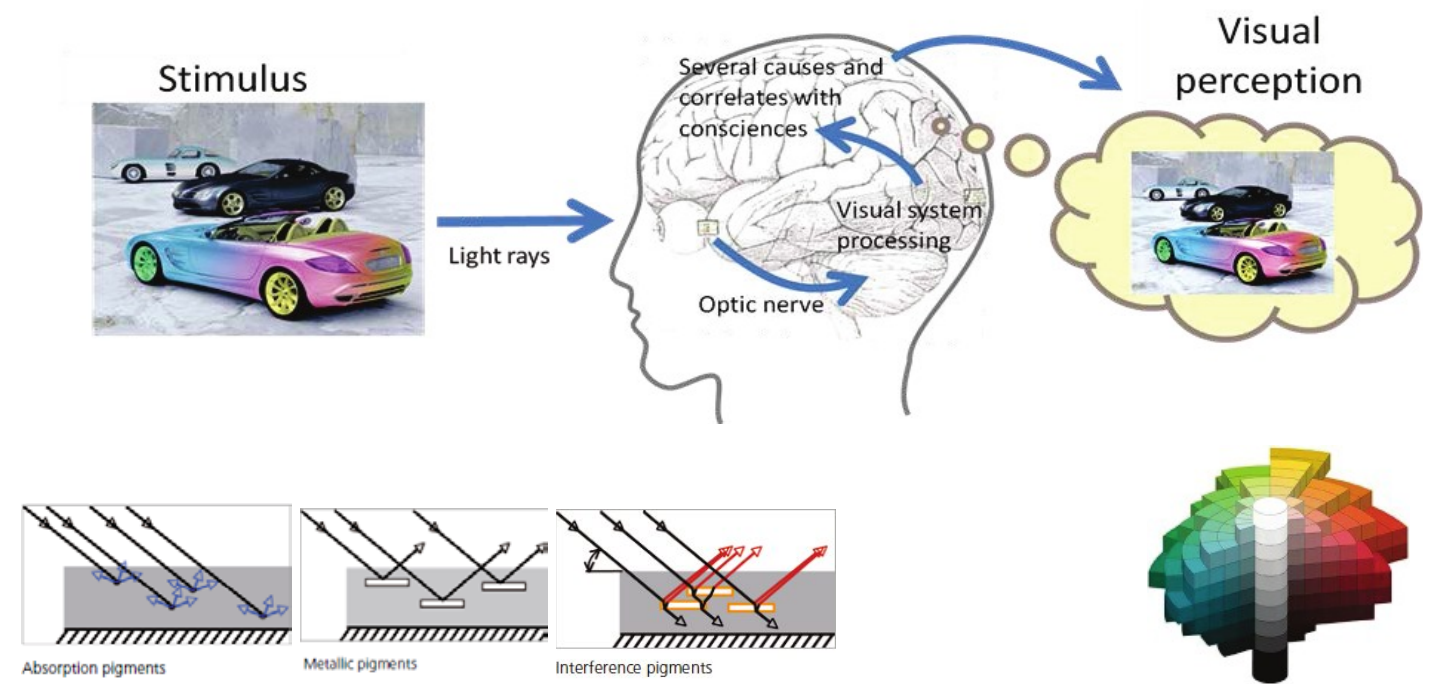

Figure 2. Light-matter-eye(brain) interaction at nano-micro (structural, left) and macroscopic (perceptual, right) level.

\subsection{Cognitive Key Objectives (TKC)}

Therefore, the learning objectives would be structured as follows:

CKO1: Understand the physic-chemical causes of color as a result of the light-matter-eye interaction;

$\mathrm{CKO}$ : Control the mathematical foundations of the encoding and graphical and numerical depiction of color and texture by the human visual system;

CKO3: Understand and know-how to measure the visual and optical properties, either normal or special (luminescent, goniochromatic, textured, functional, etc), of any material;

CKO4: Acquire a general view of the types of dyes and pigments, either organic and inorganic, with normal or special / functional behavior, and their industrial applications (Figure 3);
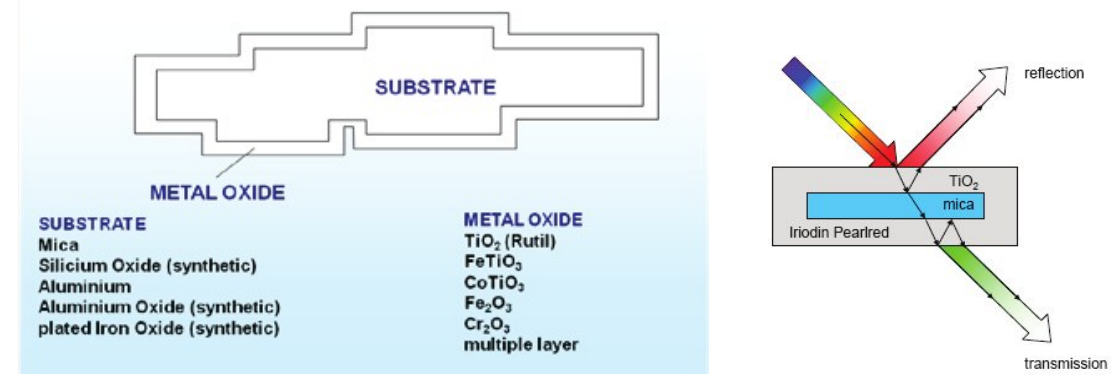

Figure 3. Scheme at nano-micro scale (left) of pigment particles with goniochromatic effect, and its perceptual and optical effect (right). 
CKO5: Acquire a general view of the raw materials involved in coatings and plastics used in the automotive sector, as well as their systems and application processes for special-effect pigments (Figure 4);

CKO6: Understand the perceptual foundations of lighting and color in order to efficiently manage the quality control of the visual harmony in the automotive sector;

CKO7: Know and compare the current methods of coloration technologies, either conventional (textile, coatings, plastics, etc) and digital (displays, printing, etc), or any innovative other;

CKO8: Understand and adapt algorithms for effectively encoding and transforming of the visual and chromatic information among multimedia devices (capture, visualization, etc) and its linking with the digital management of formulation and visual quality of gonio-apparent materials (Figure 5).
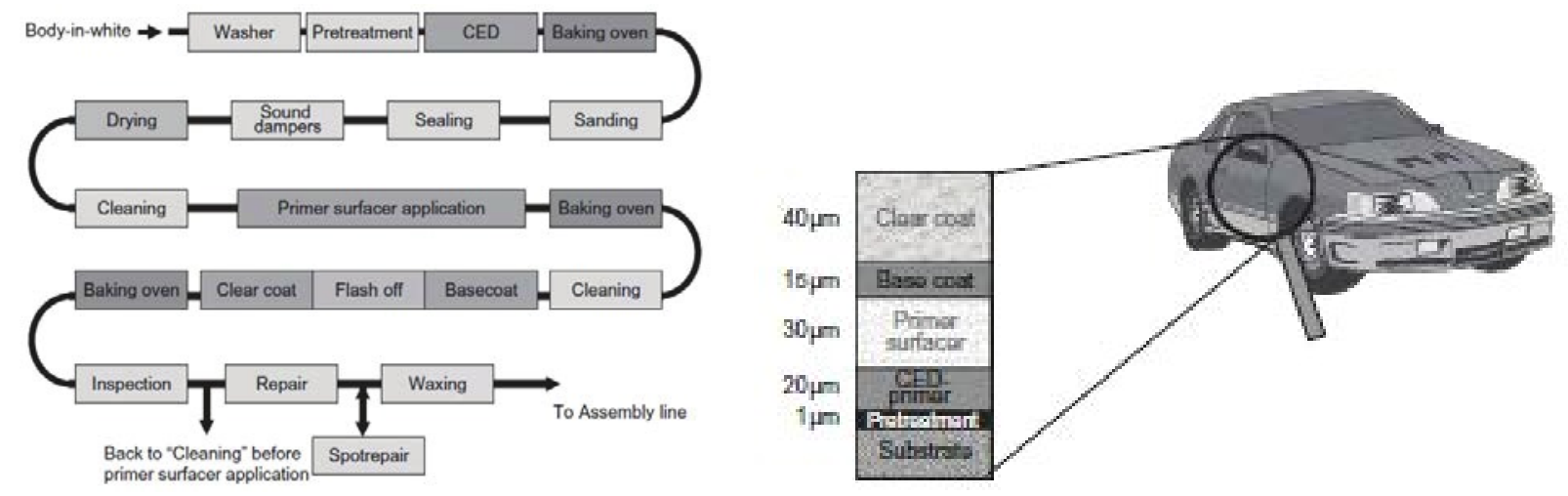

Figure 4. Steps of the conventional industrial process of painting of the car body ${ }^{4}$ (left). Micro cross section of OEM coating layer of a $\operatorname{car}^{4}$ (right).
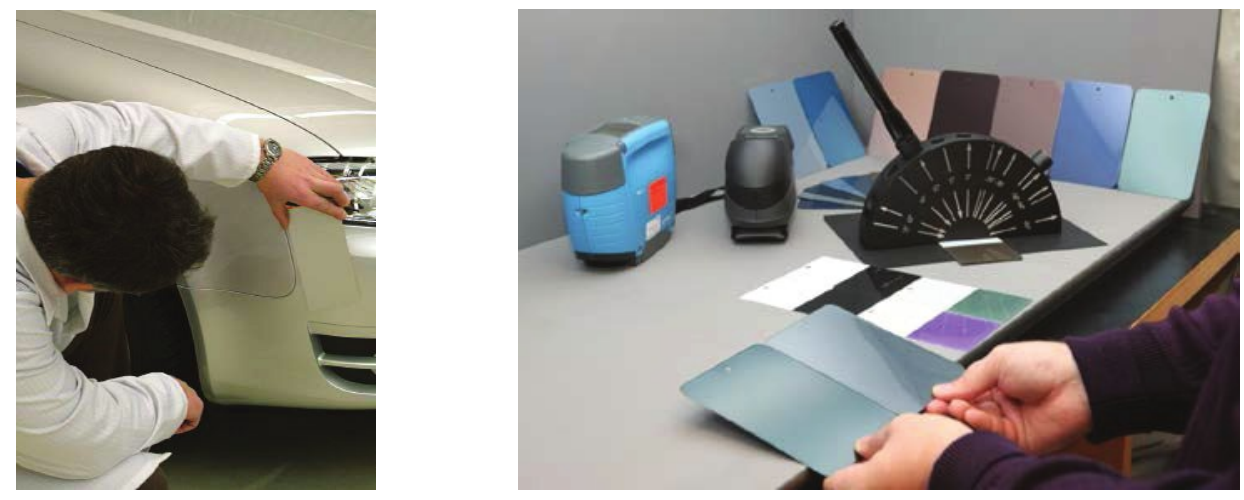

Figure 5. Example of a bad color harmony in the frontal side of a car (left); visual comparison in color, gloss and texture of a sample pair inside a diffuse lighting booth (right), with some color devices (from left to right: multi-angle spectrophotometers BYK-mac, XRite MA98 and gonio-vision-box).

\subsection{Procedural Key Objectives (PKO)}

PKO1: Measure, calculate and graph the visual (color and texture) appearance of materials, either opaque, goniochromatic, fluorescent, etc, associated with many industrial sectors;

PKO2: Calculate and graph the color difference among objects (light sources, opaque or translucent or goniochromatic materials, etc), even images, and their industrial tolerances (i.e., $\Delta$ E AUDI2000, Figure 6); 
PKO3: Characterize any type of colorant (dye or pigment), either normal or special-effect, and material able to be colored in order to be used in any system of color formulation.

PKO4: Solve the color-recipe enabling, with the controlled mixing of some colorants, on a material or substrate, to match the reference color of a previously characterized material ${ }^{6}$;

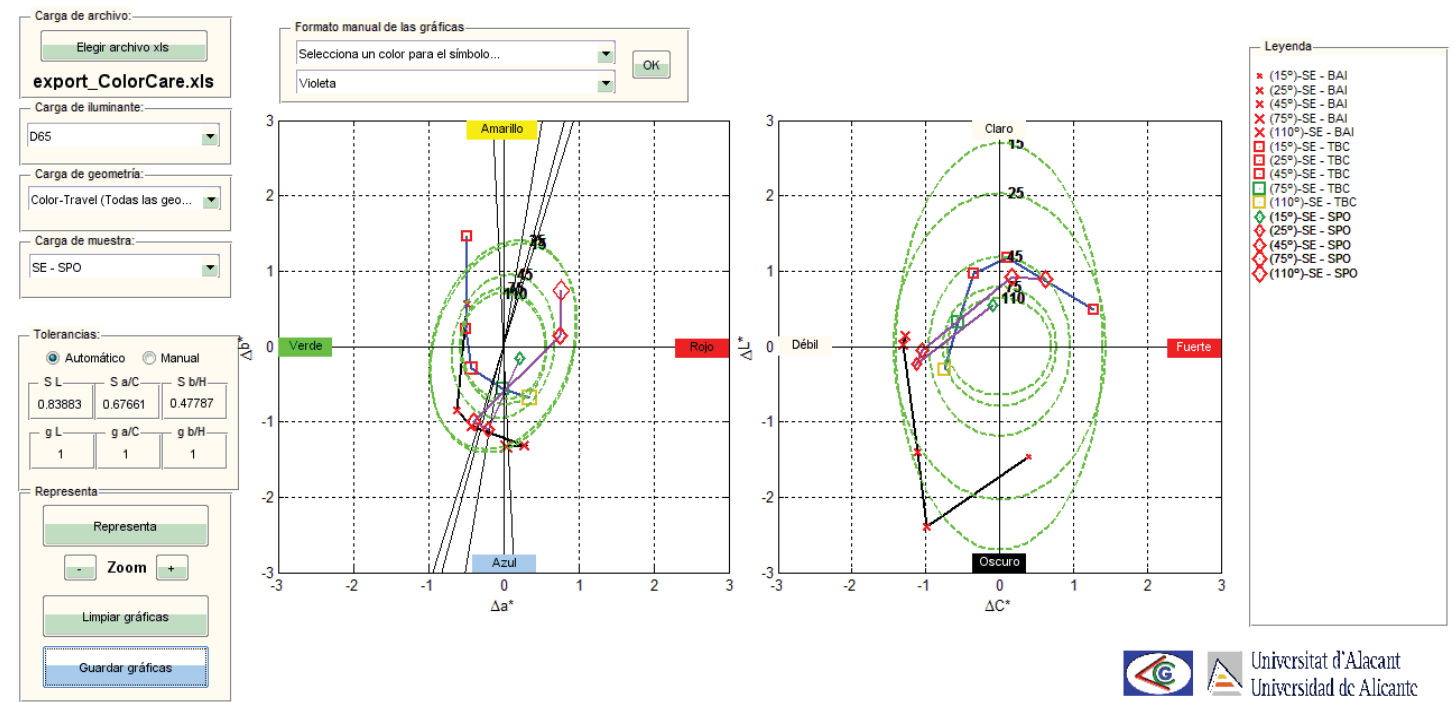

Figure 6. Color tolerances ellipses according to DE AUDI2000 formula for some components of a car body evaluating its corresponding color travel, and then its color harmony.

PKO5: Design and implement psychophysical experiments with real human observers using adequate lighting booths which efficiently manage the visual and instrumental correlation of gonio-apparent materials in many industrial applications;

PKO6: Integrate and weigh the texture and color properties of gonio-apparent materials in order to control the visual harmony of interior and exterior parts of cars (Figure 5);

PKO7: Control some commercial reference softwares in the automotive sector for management of the texture and color quality;

PKO8: Experiment with and apply quality control tests with the different systems and processes for special-effect pigments in coatings and plastics usually applied in the automotive sector.

\section{SYLLABUS, TEACHING STRATEGY AND EVALUATION METHODS}

This Master of 60 ECTS or credits (one academic year, from September to June) is managed by the Center for Postgraduate and Doctorate Studies (CEDIP), and organized by the Business School of the General Foundation of the University of Alicante and the Department of Optics, Pharmacology and Anatomy, belonging to the Faculty of Science of this University. The syllabus, taking into account the competences and learning objectives shown above, is composed by the following subjects distributed in two semesters:

CIE Colorimetry (10 ECTS),

Visual appearance (10 ECTS),

Visual harmony management (10 ECTS),

Coatings and plastics (3 ECTS),

Formulation of pigments (7 ECTS),

RTD introduction (industrial internship and Master's thesis) (20 ECTS). 
The teaching methodology will be the b-learning (blended learning), with two groups of students: on-classroom, and virtual, with mandatory laboratory practices, and condensed-level timing for providing assistance to students with employment relationship in a company.

Classroom attendance is highly recommended, with a mandatory attendance for laboratory sessions. The virtual learning activities will be diverse and demanding. These activities will be evaluated to guarantee the assimilation of general, transversal, cognitive and procedural skills. If students do not fulfill the established requirements, they will simply receive a certificate of attendance.

The Master's thesis in June will involve drawing up, presenting and defending a report on the activities undertaken during the industrial internship (car manufacturers, coatings and plastic suppliers, etc.; from March to June) or at a research institution. To do this, several companies of national and international prestige inside and outside of Spain will host ColTAS students for a period not exceeding 300 hours in the second semester (spring), and where the development activities can be conventional or RTD, always demanded and coordinated by the company and the ColTAS guidance. Exceptionally, some companies will offer some scholarships and grants for some ColTAS students. The period for receiving without cost new company collaborations will be always open. The official ColTAS website is: http://www.enegocios.ua.es/curso.asp? curso=autoingles\&edicion=528 .

The classes, both in theory and practice (with the research group "Vision and Color" at the University of Alicante, http://web.ua.es/en/gvc ), will be in the campus, and preferably evenings, Monday through Thursday, from 3 to 8 p.m.

The ColTAS teaching staff includes professors and researchers belonged to the University of Alicante, but also from other universities (UPC, UGR, and UPV) and research centers (CSIC), and professional experts currently associated with automotive companies (AUDI, BASF Coatings, BYK-Gardner, Merck, Nabersa, etc).

\section{ENTRY REQUIREMENTS, FEES AND REGISTRATION}

The ColTAS curriculum is intended for graduates in chemistry, materials, chemistry, industrial engineering, physics, optics, imaging science, computer science, mathematics, or any discipline pertaining to the quantitative description of colored materials, with a intermediate knowledge in spoken and written English. For any general information regarding registration, legalization of documents, foreign students, scholarships, insurance and issuance of degree certificates it is convenient to contact with the Center for Postgraduate and Doctorate Studies (CEDIP: $\underline{\text { http://cedip.ua.es/). }}$.

The ColTAS registration fee is $4500 €$ to be paid by installments (corporate registration available). Anyone interested in registering should complete a pre-registration form before 30th June 2013. This form is available from the course Secretary and must be handed in with a photocopy of the student's National Identity card or passport, as well as any academic transcripts and degree certificate/s. During the first half of July 2013, the Head of Studies will publish the list of admissions, which will be formalized once payment of the course deposit fee (€450, equating to $10 \%$ of the total course fee) has been confirmed in the CEDIP's Banco Sabadell account. This payment constitutes part of the first installment of the fee and will be deducted from the first installment in September.

Generally, those accepted onto the course will be required to pay course fees to the CEDIP in three installments, the first in September 2013 (50\%), the second in November 2013 (25\%) and the final installment in April 2014 (25\%).

\section{CONCLUSIONS}

The MSc degree in Color Technology for the Automotive Sector (ColTAS) of the University of Alicante (Spain) is inter and multidisciplinary one-year course covering very innovative areas such as color measurement \& perception, visual appearance of texture and color, color quality management $\&$ formulation of special-effect pigments applied in the automotive sector, as well as in other industrial sectors as cosmetics, plastics, etc. The programmed objective is to train students in advanced methodologies and models in color science and technology focused on gonio-apparent materials. With a perfect mix of relevant theoretical and practical knowledge, reinforced with internships in company, ColTAS post-graduates will be in the position to join major companies in the automotive sector, both car makers and their coatings providers, or even in other industrial sectors.

We therefore hope that this new Master, unique in its design and organization, and placing to the University of Alicante in the global vanguard of the training of new inter and multi-disciplinary professions in the XXI century, can suppose a great encouragement and outreach to improve the employability of high quality graduates and increase the scientifictechnological advances and profits in many industrial sectors. 


\section{ACKNOWLEDGEMENTS}

This academic initiative was indirectly supported by the European Union and Spanish Ministry of Economy and Competitiveness under the grant DPI2011-30090-C02-02 with European Regional Development Funds (ERDF) support.

\section{REFERENCES}

[1] Martínez-Verdú, F.M., Viqueira, V., Perales, E., Chorro, E., and Marchante, V., "Ciencia del color (2009)", Slate, 30 June $2009<$ http://ocw.ua.es/es/ciencias-de-la-salud/ciencia-del-color-2009.html> (1 June 2013).

[2] BYK-Gardner and University of Alicante, "1st BYK-Gardner Iberian Automotive Meeting”, Slate, 13 October 2011, < http://web.csidiomas.ua.es/congresos/iberianautomotive/index.html > (1 June 2013).

[3] Pfaff, G. [Special Effect Pigments], $2^{\text {nd }}$ ed., Vincentz Network, Hannover, 2008.

[4] Streitberger, H.J., Dössel, K.F., [Automotive Paints and Coatings], $2^{\text {nd }}$ ed., Wiley-VCH, Weinheim, 2008.

[5] Poth, U., [Automotive Coatings Formulation], Vincentz Network, Hannover, 2008.

[6] Klein, G., [Industrial Color Physics], Springer, New York, 2010.

*verdu@ua.es; phone +34 600948 728; fax +34 965903 464; web.ua.es/en/gvc 